$\xi=-1$

\title{
Robust Control Design of Nonlinear System by Using Back-Stepping-GSA and Sliding Mode Technique
}

\author{
Sahazati Md Rozali ${ }^{1 *}$, Rozilawati Mohd Nor ${ }^{1}$, Amar Faiz Zainal Abidin¹, Muhammad Nizam Kamarudin², Zairi \\ Ismael Rizman ${ }^{3}$
}

Centre for Robotics and Industrial Automation (CeRIA)

${ }^{I}$ Faculty of Electrical and Electronic Engineering Technology

${ }^{2}$ Faculty of Electrical Engineering

Universiti Teknikal Malaysia Melaka (UTeM), Hang Tuah Jaya, 76100 Durian Tunggal, Melaka, Malaysia

${ }^{3}$ Faculty of Electrical Engineering, Universiti Teknologi MARA, 23000 Dungun, Terengganu, Malaysia

*Corresponding authorE-mail: sahazati@utem.edu.my

\begin{abstract}
This work presents the integration of two robust controllers such as back-stepping and sliding mode controller, which is designed for nonlinear system with external disturbance injected to its actuator. Gravitational Search Algorithm (GSA) is applied to the designed controller to optimize the control and reaching law parameters for the system. The dynamics of the system is developed by consider the external force as system's nonlinearities. The tracking output and tracking error produced by combination of these two controllers is compared with the performance of classical sliding mode controller. Based on the results obtained, integration of these two controllers generates better performance than classical sliding mode controller based on its output and error.
\end{abstract}

Keywords: electro-hydraulic; back-stepping; sliding mode controller; non-linear system.

\section{Introduction}

The design of back-stepping controller is started with scalar equation that is step back toward the control input. These two signals are separated by biggest number of integration process. Since back-stepping controller has a recursive structure, its design procedure starts with a stable system and insert new controllers to stabilize outer subsystem [1]. This process is repeated until the final outer control is achieved. In comparison to the linearization method, back-stepping is able to avoid terminations of useful nonlinearities and while continue with the stabilization and tracking process. Besides, this controller has the ability to overcome the situation where the perturbation exists in the input of system by hiding the signal from the input equation. For tracking purpose, in order to develop the design process, this controller use the different between the real and reference input. Basic idea on the design procedure of this controller is explained by [1-2]. The technique is implemented in various uses such as flight control [3], automation application [4], nonlinear systems of wind turbine-based power production, electro-hydraulic actuator system [5] and robotic system. In addition, this technique also applied as a tool in parameter estimation [6] and optimal control. Besides, this control technique is used as an observer for force control of electrohydraulic actuator system and DC servo motor [7].

Sliding mode control is an alternative of control method that commonly used in nonlinear system. This control technique introduces a discontinuous signal to the system. This signal forces the system to slide along a trajectory that is always opposite from of a system's normal behavior. In order to ensure the moving of trajectories towards an adjacent region, several control structures are considered. The final chosen trajectory will move laterally the borders of the control forms. This movement is known as sliding mode. The control technique has been implied for numerous applications which are coupled-tank system [8], suspension system [9], robotic [10], underwater system [11], electromechanical system [12], induction motor system [13] and hydraulic actuator system [14-16].

Gravitational Search Algorithm (GSA) is developed by [17] created on the law of gravity and mass relations. This algorithm implied a searcher agents in a bunch of masses which communicate among them based on the laws of motion and Newtonian gravity. Instead of using trial and error to set the value of control parameter, this research work applied optimization process in order to acquire the suitable value for these parameters so that good tracking performance can be achieved. GSA is chosen to optimize these parameters. Since GSA is among a new technique in optimization field, it has not been used widely. However, there are some researchers tried to integrate GSA with PID controller [18-19] and GSA with back-stepping [20-23]. In [24], the performance of GSA with back-stepping is compared with performance of PSO with similar controller. In the controller design process for tracking system, the value of tracking error is significant. Tracking error, $e(t)$ is the dissimilarity between preferred input and real output. The error obtained is implied to design controller for the selected system based on Lyapunov Function and for optimization process. As nonlinear controller, back-stepping and sliding mode controllers have their capability and limitation. Several studies combine these two nonlinear controller such that their own strength can support to each other weaknesses. In [25] integrate these two controllers to increase the tracking performance of permanent magnet synchronous motor control system. Combination of these two controllers also been proved too has robustness to the exterior 
disturbances and virtuous flexibility to variation of the parameter of a coupled-tank system [26]. A vane-type air motor X-Y table motion system also adapts these two control techniques for tracking purpose [27] and to overcome chaotic problem [28]. Besides, combination of these method with neural networks to develop a controller for a strict feedback form system which has unidentified uncertainties and instabilities [29]. Additional integration of them also can be found in [30] to stabilize the cart pendulum system and [31] for unmanned aerial vehicle. In [32-33] also integrate these two controllers for two different nonlinear systems.

This research performs a controller development for a nonlinear system which associates two different controllers, which are backstepping and sliding mode controller to enhance the tracing presentation of the system. Gravitational Search Algorithm (GSA) is integrated to the designed controller such that it is automatically fine-tune the control constraints based on the dynamic variations of that system. Constant force is injecting to the system as an external disturbance such that it will disturb the dynamic of the system. The valuation of the tracking presentation of it is shown based on its tracking error and output by looking at the value Sum of Squared Error (SSE). This assessment is compared with the output of the classical sliding mode controller with similar index performance.

\section{System Dynamic}

Electro-hydraulic actuator (EHA) is one of a non-linear system with uncertain changing aspects. This work involves the process of external disturbance is injected to the actuator of electro hydraulic actuator system (EHA). It considers Sum of Squared Error (SSE) as an objective function for optimization process because the position tracing of this system is highly nonlinear [34-35]. A model of this system is represented as

$\tilde{x}_{1}=x_{2}$

$\tilde{x}_{2}=-\frac{k}{m} x_{1}-\frac{f}{m} x_{2}+\frac{s}{m} x_{a}-\frac{F_{L}}{m}$

$\tilde{x}_{\mathrm{a}}=-\frac{s}{k_{c}} x_{2}-\frac{k_{\mathrm{l}}}{k_{c}} x_{\mathrm{a}}+\frac{c}{k_{c}} \sqrt{\frac{p_{a}-x_{\mathrm{a}}}{2}} k_{\mathrm{v}} u$

$x_{1}$ is movement of the load, $x_{2}$ is load speed and $x_{a}$ is differential pressure $p_{1}-p_{2}$ among the cylinder compartments. $F_{L}$, a constant or time-varying signal is external disturbance injected to the system. The parameter of this system is shown in Table 1 [5].

Table 1: Parameter of the tested system

\begin{tabular}{|c|c|}
\hline Load at the EHS rod, $m$ & $0.33 \mathrm{Ns}^{2} / \mathrm{cm}$ \\
\hline Piston area, 5 & $10 \mathrm{~cm}^{2}$ \\
\hline Coefficient of viscous friction, $f$ & $27.5 \mathrm{Ns} / \mathrm{cm}$ \\
\hline Coefficient of aerodynamic elastic force, $k$ & $1000 \mathrm{~N} / \mathrm{cm}$ \\
\hline Valve port width,W & $0.05 \mathrm{~cm}$ \\
\hline Supply pressure, $P_{a}$ & $2100 \mathrm{~N} / \mathrm{cm}^{2}$ \\
\hline $\begin{array}{c}\text { Coefficient of volumetric flow of the valve } \\
\text { port, } \epsilon_{d}\end{array}$ & 0.63 \\
\hline $\begin{array}{l}\text { Coefficient of internal leakage between the } \\
\text { cylinder chambers, } k_{l}\end{array}$ & $2.38 \times 10^{-3} \mathrm{~cm}^{5} / \mathrm{Ns}$ \\
\hline Coefficient of servo valve, $k_{v}$ & $0.017 \mathrm{~cm} / \mathrm{V}$ \\
\hline $\begin{array}{c}\text { Coefficient involving bulk modulus and } \\
\text { EHA volume, } k_{e}\end{array}$ & $2.5 \times 10^{-4} \mathrm{~cm}^{5} / \mathrm{N}$ \\
\hline Oil density $\rho$ & $8.87 \times 10^{-7} \mathrm{Ns}^{2} / \mathrm{cm}^{4}$ \\
\hline
\end{tabular}

\section{Controller Design}

A robust control for a plant with uncertainty might be designed by using a combination of back-stepping and sliding mode control techniques. In this section, a systematic design procedure is proposed to develop these two control techniques. The design process is started by defining the Lyapunov function as

$V_{1}=\frac{1}{2} e_{1}^{2}$

$V_{2}=V_{1}+\frac{1}{2} e_{2}^{2}$

$V_{a}=V_{a}+\frac{1}{2} s^{2}$

with $€$ is tracking error for each state while $s$ is sliding surface for sliding mode controller. Based on these Lyapunov functions, the control signals for back-stepping sliding mode controller for this system can be derived as

$x_{2 d}=-k_{1} e_{1}+\tilde{x}_{1 d}$

$x_{a d}=\frac{m}{s}\left[-e_{1}+\frac{k}{m} x_{1}+\frac{f}{m} x_{2}+\frac{F_{L}}{m}+\dot{x}_{2 d}-k_{2} e_{2}\right]$

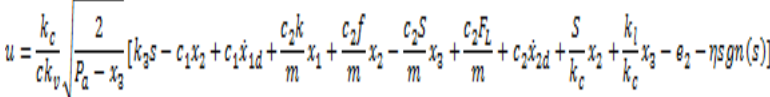

The designed control signal for sliding mode controller is given as

$u=\frac{k_{c}}{c k_{v}} \sqrt{\frac{2}{P_{a}-x_{a}}}\left[-\tau \operatorname{sgn}(s)-k_{1} s+\frac{k}{m} x_{1}+\frac{f}{m} x_{2}-\frac{s}{m} x_{2}+\frac{F_{L}}{m}+\frac{k_{l}}{k_{e}} x_{2}-c_{1} x_{2}+c_{1} \dot{x}_{1}\right]$

\section{Optimization}

This research considers Sum of Squared Error (SSE) as an objective function in optimization of control and Lyapunov parameters. The formula of SSE is given in (11).

$S S E=\sum_{i=1}^{n}\left(x_{i}-y_{\text {ref }}\right)^{2}$

where SSE stands for sum of squared error, $i$ is number of iteration, $\mathrm{x}_{\mathrm{i}}$ is system output at $i$ iteration and $y_{\mathrm{ref}}$ represents reference input. A good tracking response will give smaller SSE.

\section{Results and Discussion}

This section presents the analysis of tracking performance of the designed controller.

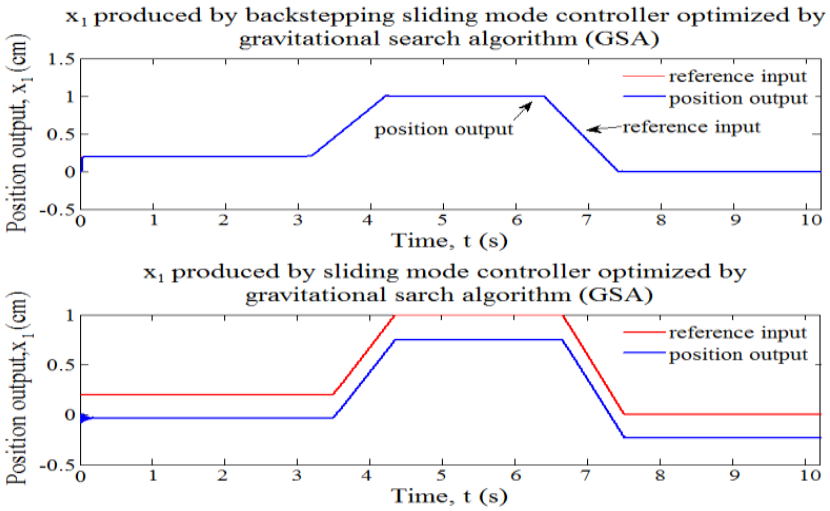

Fig. 1: $x_{1}$ produced by integration of back-stepping and sliding mode controller and classical sliding mode controller 
The upper plot in Figure 1 shows the output formed by combination of sliding mode controller and back-stepping while the lower plot illustrates the output produced by classical sliding mode controller. Referring to the figure, combination of sliding mode controller and back-stepping yield better system's output. Its tracking error is almost zero compared to the classical sliding mode controller only. The output of the system tracked the reference input smoothly. Although the system with sliding mode controller managed to track the shape of the reference input, its tracking error is bigger than the top plot. This scenario is proved in error plot in Figure 2.

Position tracking error, e produced by backstepping sliding mode controller optimized by using gravitational search algorithm

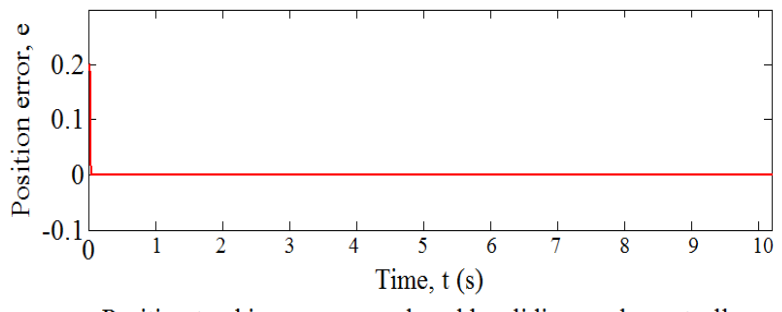

Position tracking error,e produced by sliding mode controller optimized by using gravitational search algorithm

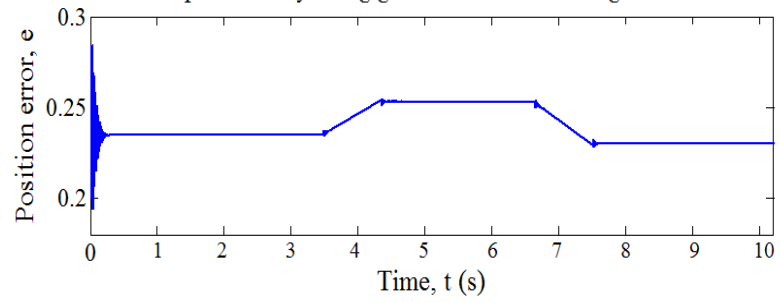

Fig. 2: Tracking error value generated by combination of back-stepping and sliding mode controller and classical sliding mode controller

The first plot in Figure 2 shows the error generated by integration of back-stepping and sliding mode controller, while the second plot illustrates the error produced by classical sliding mode controller. The figure shows that integration of back-stepping and sliding mode controller yield zero error but classical sliding mode controller produced around 0.2 error. This result proved that integration of sliding mode controller with back-stepping produced better performance.

Figure 3 illustrates the sliding surface, $s$ of combination of backstepping with sliding mode controller and classical sliding mode controller.
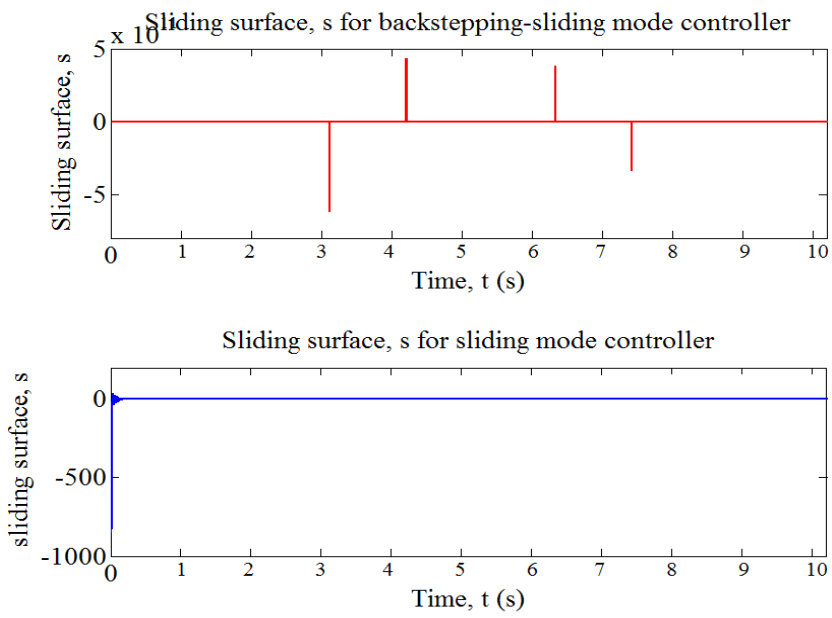

Fig. 3: Sliding surface, $s$ for combination of back-stepping and sliding mode controller and classical sliding mode controller

By looking at Figure 3, the upper graph shows the sliding surface, $s$ for integration of back-stepping and sliding mode controller while the lower graph presents $s$ for classical sliding mode controller. Both graphs proved the condition $s=s=0$, which means the stability of the system is accomplished.

Figure 4 demonstrates the control signal, $u$ produced for the designed controller.

Control signal, u produced by backstepping-sliding mode controller

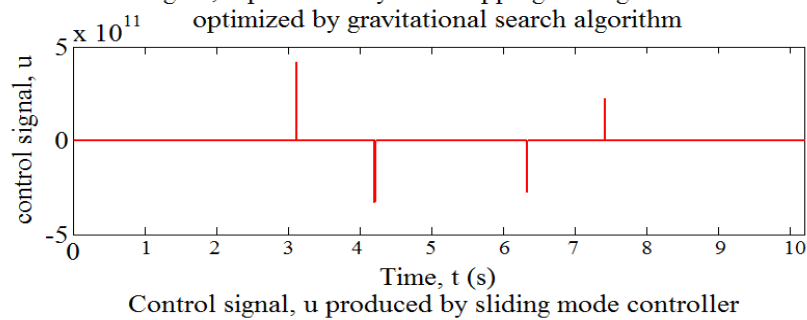

Control signal, u produced by sliding mode controlle optimized by gravitational search algorithm

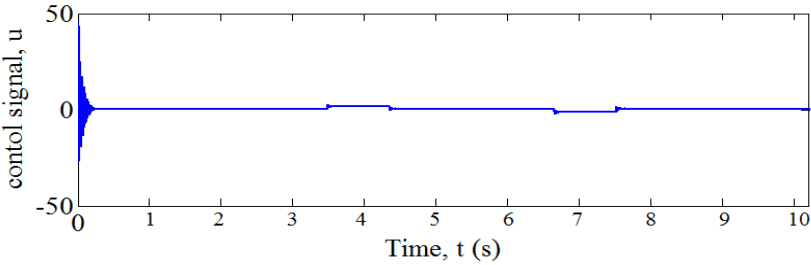

Fig. 4: Control signal, $u$ for designed controller

Referring to Figure 4, the upper plot shows the control signal, $u$ produced by combination of sliding mode controller and backstepping while the similar signal generated by classical sliding mode controller is shown in the bottom plot. The figure shows that plain control signal is produced by integration of sliding mode controller and back-stepping, while the classical sliding mode controller produced control signal with small chattering.

\section{Conclusion}

This work proposed integration of back-stepping with sliding mode controller for nonlinear system. Since the designed controller consists of several controls and reaching law parameter, Gravitational search algorithm (GSA) technique is applied to search for optimum value of these parameters. Therefore, the designed controller has an adaptation ability to vary its parameters repeatedly regarding to the systems dynamic. The results obtained are compared with the designed classical sliding mode controller. Referring to the results, integration of sliding mode and back-stepping controller yields better tracking performance than classical sliding mode controller itself. It can be proved by smooth tracking plot, smaller tracking error and less chattering in control signal. The stability of the designed controller also is verified by Lyapunov Function.

\section{Acknowledgement}

This work was supported in part by UTeM under Grant Nos. PJP/2018/FTK(17C)/S01643.

\section{References}

[1] K. I. Kristic, M. I. Kanellakoupulos, P. V. Kokotovic, Nonlinear and adaptive control design. John Wiley and Sons, 1995.

[2] H. K. Khalil, Nonlinear systems. Prentice Hall, 2002.

[3] Z. E. Fang, M. S. Queiroz, D. M. Dawson, Global output feedback control of dynamically positioned surface vessel: An adaptive control approach. Mechatronics, 14, 341-356, 2004.

[4] A. Karimi, A. Al-Hinai, K. Schoder, A. Feliachi, Power system stability enhancement using backstepping controller tuned by particle swarm optimization technique. Proceedings of the IEEE Power Engineering Society General Meeting, 2005, pp. 3055-3060.

[5] I. Ursu, F. Ursu, F. Popescu, Backstepping design for controlling electrohydraulic servos. Journal of Franklin Institute, 343, 94-110, 2006. 
[6] P. Nakkarat, S. Kuntanapreda, Observer-based backstepping force control of an electrohydraulic actuator. Control Engineering Practice, 17, 895-902, 2009.

[7] B. M. B. A. Farrokh Payam. Nonlinear sliding mode controller for sensorless speed control of DC servo motor using adaptive backstepping observer. Proceedings of the International Conference on Power Electronics, Drives and Energy Systems, 2006, pp. 1-5.

[8] N. B. Almutairi, M. Zribi, Sliding mode control of coupled tanks. Mechatronics, 16, 427-441, 2006.

[9] Y. Md. Sam, J. H. S. Osman, M. Ruddin A. Ghani, A class of proportional-integral sliding mode control with application to active suspension system. Systems and Control Letters, 51, 217-223, 2009.

[10] H. Liu, Z. Gong, Upper bound adaptive learning of neural network for the sliding mode control of underwater robot. Proceedings of the International Conference on Advanced Computer Theory and Engineering, 2008, pp. 276-280.

[11] A. Bagheri, Jalaljavadimoghaddam, Simulation and tracking control based on neural-network strategy and sliding-mode control for underwater remotely operated vehicle. Neurocomputing, 72, 1934-1950, 2009.

[12] I. Eker, Sliding mode control with PID sliding surface and experimental application to an electromechanical plant. ISA Transactions, 45(1), 109-118, 2006.

[13] O. Barambones, P. Alkorta, Aitor J. Garrido, I. Garrido, F. J. Maseda, An adaptive sliding mode control scheme for induction motor drives. International Journal of Circuits, Systems and Signal Processing, 2007, 1(1), 73-78.

[14] M. Hsiung Chiang, L. Wang Lee, H. H. Liu, Adaptive fuzzy sliding-mode control for variable displacement hydraulic servo system. Proceedings of the International Conference on Fuzzy Systems, 2007, pp. 1-6.

[15] H. M. Chen, J. C. Renn, J. P. Su, Sliding mode control with varying boundary layers for an electro-hydraulic position servo system. International Journal of Advanced Manufacturing Technology, 26, 117-123, 2005.

[16] M. Mihajlov, V. Nikolić, D. Antic, Position control of an electrohydraulic servo system using sliding mode control enhanced by fuzzy PI controller. Facta Universitatis Series: Mechanical Engineering, 1(9), 1217-1230, 2002.

[17] E. Rashedi, H. N. Pour, S. Saryazdi, GSA: A gravitational search algorithm. Information Sciences, 179, 2232-2248, 2009.

[18] S. Duman, D. Maden, U. Güvenç, Determination of the PID controller parameters for speed and position control of DC motor using gravitational search algorithm. Proceedings of the International Conference on Electrical and Electronics Engineering, 2011.

[19] H. Shayeghi, A. Ghasemi, Optimal tuning of PID type stabilizer and AVR gain using GSA technique. International Journal on Technical and Physical Problems of Engineering, 4(2), 98-106, 2012.

[20] S. M. Rozali, M. F. Rahmat, A. R. Husain, M. N. Kamarudin, Design of adaptive backstepping with gravitational search algorithm for nonlinear system. Journal of Theoretical and Applied Information Technology, 59(2), 460-468, 2014.

[21] K. K. Ahn, D. N. C. Nam, M. Jin, Adaptive backstepping control of an electrohydraulic actuator. IEEE/ASME Transactions on Mechatronics, 19(3), 987-995, 2014.

[22] M. A. M. Basri, A. R. Husain, K. A. Danapalasingam, GSA-based optimal backstepping controller with a fuzzy compensator for robust control of an autonomous quadrotor UAV. Aircraft Engineering and Aerospace Technology: An International Journal, 87(5), 493-505, 2015.

[23] S. Md. Rozali, M. F. Rahmat, A. R. Husain, M. N. Kamarudin, Robust Controller design for position tracking of nonlinear system using backstepping-GSA approach. ARPN Journal of Engineering and Applied Sciences, 11(6), 3783-3788, 2016.

[24] S. Md. Rozali, M. F. Rahmat, A. R. Husain, Performance comparison of particle swarm optimization and gravitational search algorithm to the designed of controller for nonlinear system. Journal of Applied Mathematics, 2014, 1-9, 2014.

[25] Y. Qian, L. Weiguo, H. Yongping, Real time simulation study on backstepping sliding mode control of permanent magnet synchronous motor. Proceedings of the International Conference on Electrical Machines and Systems, 2011, pp. 1-5.

[26] R. Benayache, L. Chrifi-Alaoui, A. Benamor, X. Dovifaz, P. Bussy, Robust control of nonlinear uncertain systems via sliding mode with backstepping design. Proceedings of the American Control Conference, pp. 4695-4700, 2010.
[27] C. H. Lu, Y. R. Hwang, Y. T. Shen, Backstepping sliding mode tracking control of a vane-type air motor X-Y table motion system. ISA Transactions, 50, 278-286, 2011.

[28] P. Hu, G. Cai, L. Yao, X. Fang, Recursive backstepping nonlinear control and sliding mode control of a novel hyperchaotic finance system. Proceedings of the 2nd International Conference on Computer and Information Application, pp. 0777-0780, 2012.

[29] D. Liu, P. Yang, J. Wu, A combined multiple sliding mode and backstepping design to robust adaptive neural control for uncertain nonlinear systems. Proceedings of the 5th International Conference on Biomedical Engineering and Informatics, pp. 1221-1226, 2012

[30] N. Adhikary, C. Mahanta, Integral backstepping sliding mode control for underactuated systems: Swing-up and stabilization of the cart-pendulum system. ISA Transactions, 52(6), 870-880, 2013.

[31] H. Khebbache, M. Tadjine, Robust fuzzy backstepping sliding mode controller for a quadrotor unmanned aerial vehicle. Journal of Control Engineering and Applied Informatics, 15(2), 3-11, 2013.

[32] D. Elleuch, T. Damak, Backstepping sliding mode controller coupled to adaptive sliding mode observer for interconnected fractional nonlinear system. Recent Advances in Telecommunications, Signals and Systems, pp. 130-138, 2013.

[33] S. Zeghlache, D. Saigaa, K. Kara, A. Harrag, A. Bougerra, Backstepping sliding mode controller improved with fuzzy logic: application to the quadrotor helicopter. Archives of Control Sciences, 22(2), 255-282, 2012. 